\title{
National geological surveys: Their present and future roles
}

We live in a time of rapid and unexpected changes. The political map of the world is being transformed at a remarkable pace and in unanticipated directions. The news media abound with stories about the threat of ominous global changes in the geosphere and the biosphere, changes that are the cumulative result of human activities. The present rate of growth in the human population, in the use of natural resources, and in the human impacts on the environment for life on Earth is unique in the entire history of humankind. Environmental impacts are assuming increasing importance in policy making. Patterns of natural resource exploration, production, and use are changing now in response to their environmental consequences, as well as to shifting markets. New technologies have transformed the nature, scope, and effectiveness of the activities of the geologi cal surveys. It seems that the past is no longer a reliable guide to the future. Moreover, under today's rapid pace of change, the distinction between the present and the future is becoming blurred; and the present role of the national geological surveys is coalescing with their future role, which now truly begins tomorrow.

I am reminded of the proverb: "To prophesy is extremely difficult-especially with respect to the future." Accordingly, rather than attempt to address directly the question of the present and future roles of geological surveys now, I will consider some other basic questions initially. Does the basic purpose of a national geological survey differ significantly from one country or region to another? Or are there generalities that apply globally? What should governments expect in return for using today's scarce financial resources to meet the costs of maintaining national geological surveys? Are national geological surveys required in our modern world, or are they unnecessary vestiges of a former era?

Let me consider some generalities first.

\section{The mission of a national geological survey}

To govern, governments require information. They require information in order to identify and analyze national problems and opportunities, to make sound public policy decisions, and to implement these decisions. To be most effective, the information must be impartial and trustworthy. Moreover, in a democracy, the essence of the information also must be available and understandable to the people on behalf of whom the governments act and to whom they are accountable.

\section{National geological surveys are in the geological information business. They exist in order to meet the geoscience information requirements of a nation. . .}

Geoscience information is required by governments for the development of sound public policies on, among other things, the management of mineral, energy, and water resources; the management of risk due to geological and geophysical hazards such as floods, landslides, earthquakes, and volcanic eruptions; and the protection of the environment and human health, both nationally and globally.
Geoscience information also is required by governments for use as an instrument of public policy. For example, the information is made available by governments to the general public or to specific target audiences, such as the mineral or petroleum exploration industries, in order to stimulate regional or national development of natural resources, to reduce the risk due to natural hazards, or to promote environmentally sound economic development.

Geoscience information and expertise are a special kind of national resource for any nation on Earth. Unlike many other kinds of scientific information and expertise, geoscience information and expertise have both local and universal significance. They pertain to a specific place in a specific country, as well as to the global corpus of scientific knowledge. They are part of the knowledge base concerning the nature and present state of a country. Along with information on the rest of the natural environment, on the size and nature of the national population, on the economy, and on the national and international political environment, they form an integral part of the information framework within which any government governs and any nation functions.

In order to function effectively, a nation needs a source of impartial and scientifically trustworthy geoscience information and expertise. National geological surveys meet this need by conducting field research and related laboratory research; by compiling information available from State or Provincial agencies, universities, industry, and various other sources; and by using all of this to maintain a national geoscience knowledge base from which the needed geoscience information and advice can be extracted as required. The national geoscience knowledge base is an important national resource, but it becomes depleted as science advances if it is not updated continually. In order to maintain the vitality of a national geoscience knowledge base, the time required for the research, including the systematic geological surveys, is longer than the lifetime of many national policy issues. Therefore, good strategic planning is crucial to the effective operation of national geological surveys. Feedback relationships between the national knowledge base and those geoscience activities that are instruments for the implementation of public policies offer important opportunities for maintaining and strengthening the knowledge base. These considerations are the basis for my convictions concerning the need for, and the purpose of, a national geological survey, even in these times of scarce financial resources.

The basic mission of any modern national geological survey is to ensure the availability of the geoscience information and expertise that are required for the wise use of the nation's mineral, energy, and water resources, for the health and safety of its people, and for the protection of the environment. This is true for any nation on Earth.

\section{Historical perspective}

Since the first national geological survey was created in Great Britain just over 150 years ago, national geological surveys have been established in most countries throughout the world for the purpose of ensuring that governments have the geoscience information and expertise that they need to function properly. The geological surveys have provided scientifically verifiable information and expert advice to governments, and they have served as national instruments for promoting investment in and development of mineral and mineral fuel resources.

The scope of the work of the national geological surveys and the relative importance of the various applications of their geoscience 
information and expertise have changed dramatically over the years, but their basic mission remains unchanged. The romantic era of the preliminary geological exploration of vast new areas and of the search for obvious, easy-to-find mineral and energy resource bonanzas has been replaced by a new era of technologically sophisticated research, commonly conducted by large interdisciplinary teams or networks. State and Provincial geological surveys, the universities, and the exploration research components of mining and petroleum companies have made increasingly important contributions to national requirements for geoscience information and expertise; however, none of these agencies can be completely committed in the nature and scope of their work to fulfilling the national requirements because they all must "march to the beat of a different drummer." Growing concerns about water resources, environmental constraints on economic development, the impact of human activities on the environment and public health, and public safety have created new demands for national geoscience information and expertise, as well as new tasks for national geological surveys. In spite of all of these new developments, the basic mission of a national geological survey still can be described as being "to ensure the availability of the geoscience information and expertise required to promote the wise use of the nation's natural resources and the safety, health, and well being of its people."

\section{Future needs}

Environmentally sound resource development, which is necessary in order to meet the needs of the explosive growth in the human population, and the reduction of risk to human health and safety are both important policy issues in our current climate of rapid and unexpected changes. They most certainly will be preeminent policy issues in the near future as both the human population and the demand for globally sustainable development continue to grow. In order to illustrate what I mean, I would like to point out that when I began working for the Geological Survey of Canada the size of the human population was about $21 / 2$ billion; just before I retired, it had passed 5 billion. More people had been added to the human population during that 35-year period than during all of the preceding history of humankind. Furthermore, during that period, we also had substantial growth in the per capita use of mineral and energy resources and in the per capita contribution to the degradation of the global environment. Barring some global catastrophe, it seems inevitable that, as we move into the 21 st century, we will see continued growth in the human population; in the demand for energy, mineral, and water resources; and in the threat to human safety, human health, and the environment for life on Earth. Accordingly, I believe that it is safe to conclude that the need for an impartial, trustworthy national source of geoscience information and expertise will grow in the immediate future in every major country in the world. I also believe that the reconciliation between resource exploration, production, and use on one hand and the protection of the environment on the other will be the central issue globally inducing changes in what geological surveys do and how they do it.

\section{Opportunities}

In addition to the changes ahead for national geological surveys as a result of the concern about environmental impacts, rapid advances in the development of new technologies will drive further changes in the activities of geological surveys. New, rapid, relatively low cost, high-precision observational and analytical technologies have created new opportunities for the acquisition of geophysical, geochemical, and geochronological data that have transformed the geoscience of the continents. They offer the prospect for major advances on problems that extend geological surveys down into the third dimension, depth, and back into the fourth dimension, time. In the third dimension, the geological surveys can address fundamental problems such as the search for deeply buried mineral resources, the storage of toxic wastes, and the cleanup of contaminated groundwater systems. In the fourth dimension, the geological surveys can address problems relating to Earth's history, particularly Precambrian time, the first four-fifths of the planet's history, which lacks adequate fossils for precise biostratigraphic dating. New technologies for the storage, retrieval, analysis, and display of data, particularly the geographically referenced data that are the main concern of geological surveys, offer extraordinary opportunities for improving the effectiveness of the geological surveys in performing their research and in communicating with their clients. Geographic information systems and capabilities for high-speed digital data transmission are revolutionizing the way geological surveys operate.

\section{Challenges}

Geological mapping has been, is now, and will be a primary activity of national geological surveys as they enter the 21 st century. It is unfortunate that "geological mapping" is an activity whose real nature is obscured by its name. Contrary to what may be implied by the term "mapping," geological mapping is a basic field research activity. It involves the use of a variety of techniques from the most mundane to the most sophisticated new technology; but whatever the technique, its basic purpose is to establish the nature, the threedimensional shape and position, the origin, the age and evolution, and the regional or global significance of bodies of rock. It involves the recognition, description, analysis, and interpretation of experiments that have been conducted by nature and that hold the key to the wise use of the Earth by humankind.

\section{. . geoscience information and expertise have both local and universal significance.}

The new frontier for geological mapping is in the third dimension: depth. In the past, most geological mapping has been essentially two dimensional and limited to what is exposed at the Earth's surface, is revealed by rare boreholes, and is inferred by projections into the subsurface. Emerging new technologies for geophysical remote sensing, such as those that have transformed the petroleum exploration industry, offer the prospect for dramatic advances in the mapping of geology at depth; and this offers the prospect for major new mineral resources. For example, over vast areas of the continents, basement rocks similar to those that have provided much of the world's mineral wealth are buried beneath younger sedimentary rocks, but they occur at depths that could be mined if we could identify the mineral deposits. One of the challenges for the emerging new technologies is to find those new mineral resources.

\section{Information and communication}

National geological surveys are in the geological information business. They exist in order to meet the geoscience information requirements of the nation, as defined and redefined from time to time by the government. Their welfare and their survival are contingent upon their success in identifying and satisfying the needs of their clients.

In order to be effective in the public policy process, geoscience information and advice must be user friendly and credible. It must be 
timely, succinct, and completely understandable in terms of its significance, scope, and limitations. At the same time, it must meet the highest standards of scientific quality and credibility. This can be achieved only by maintaining an open dialog between the scientists and the people who will use this information and expertise, by employing the best available scientific talent, by fostering scientific creativity, and by ensuring a thorough scientific peer review of the science. Public policy issues demand specific, quantitative, "derivative" geoscience information, such as assessments of the resource potential or the earthquake risk in a specific area or the expected oil and natural gas endowment of the nation. Systematic, impartial, authoritative geoscientific studies provide the only rational basis for answering these questions, but the time required to conduct the necessary research is commonly much longer than the duration of the public policy issue or of a specific government. Consequently, it is vital that challenges, problems, and opportunities be anticipated and that financial and human resources be deployed strategically.

Good strategic planning is crucial to the effective operation and survival of national geological surveys. Strategic planning must seek to ensure the availability of the knowledge and expertise that will be required to address policy issues as they emerge in the future. This involves taking into consideration new or emerging policy directions of governments and new or emerging scientific concepts that may lead to a reevaluation of existing scientific data or to the need for new data. This also involves providing for the availability of the professional expertise that will be needed in the future. Geoscience expertise generally is developed through experience in studying specific areas or regions and, therefore, is not entirely transferable, nor can it be generated rapidly to meet new demands. Successful investments in the development of professional expertise require great foresight and careful planning.

New technologies have
transformed the nature, scope, and
effectiveness of the activities
of the geological surveys. It seems
that the past is no longer
a reliable guide to the future.

The geoscience information and expertise that are acquired in order to meet the needs of national governments for the development of policies can be made available then to the general public at low added cost. When geoscience information is used as a instrument of public policy to reach specific target audiences, such as mineral and energy resource exploration companies that might stimulate regional economic development or such as citizens who are threatened by the risks associated with natural hazards like earthquakes and flooding, this information may be provided free of cost as a "public good," or it may be treated as a marketable commodity and sold at reduced prices. However, it also may be treated primarily as a source of national revenue and sold at market prices to other government agencies, to resource development companies, to consultants, or to geoscience service companies. In some countries, the role for the national geological survey has been shifting away from service to the government and the general public toward that of a profit center based on the sale of professional services and geoscientific information on the open market in competition with private companies. In a free enterprise society, this trend inevitably must lead to the demise of the national geological survey because it cannot succeed in fulfilling two conflicting missions simultaneously.

\section{Conclusions}

National geological surveys are in the geological information business. They exist in order to meet the geoscience information requirements of a nation, as defined and redefined from time to time by the government. Their welfare and their survival are contingent upon their success in identifying and satisfying the needs of their clients.

The 21 st century will provide new challenges and new opportunities for national geological surveys throughout the world. Emerging global crises that are arising from the growth in the human population, the per capita use of resources, and the resulting depletion of natural resources and deterioration of the environment for human habitation will present governments worldwide with urgent needs for geoscience information and expertise about areas both within and beyond their national borders. The potential future role for national geological surveys is very large; the actual future role will depend on many factors, not the least of which will be the leadership displayed by the national geological surveys both individually and collectively.

\section{Acknowledgments}

My views on the present and future roles of national geological surveys originated with my experiences in the management of the Geological Survey of Canada, where they were strongly influenced by John Fyles, Bill Hutchison, and Digby McLaren. However, they also reflect helpful comments provided by E-an Zen, Brian Skinner, Roye Rutland, Dallas Peck, Martin Kürsten, Umberto Cordani, and Peter Cook in response to a written request from me.

(Address to the International Conference of Geological Surveys that was held in Ottawa. Ontario, Canada, on the occasion of the 150th anniversary of the Geological Survey of Canada in April 1992. Copies of the proceedings will be available from the Geological Survey of Canada in late 1992.) $\square$

Raymond A. Price Queen's University Kingston, Ontario. Canada 